\title{
Erratum to: Annexin 1 protects against apoptosis induced by serum deprivation in transformed rat retinal ganglion cells
}

\author{
Jingbo Sun · Zhengbo Shao • Yuanhang Yang • \\ Donglai Wu $\cdot$ Xuemei Zhou $\cdot$ Huiping Yuan
}

Published online: 29 June 2012

(C) Springer Science+Business Media B.V. 2012

Erratum to: Mol Biol Rep (2012) 39(5):5543-5551

DOI 10.1007/s11033-011-1358-1

In the published article, there is an error in author names, which is corrected in this erratum.

The online version of the original article can be found under doi: 10.1007/s11033-011-1358-1.

J. Sun $\cdot$ Z. Shao $\cdot$ Y. Yang $\cdot$ D. Wu $\cdot$ X. Zhou $\cdot$ H. Yuan $(\bowtie)$ Department of Ophthalmology, The 2nd Affiliated Hospital, Harbin Medical University, 246 Xuefu Road, Harbin 150086, Heilongjiang, People's Republic of China

e-mail: yuanhp@yahoo.com 